Bojan Žalec

\title{
Bivanjsko upanje, smisel in resonanca ${ }^{1}$
}

\section{Existential Hope and Meaning of Life, and Resonance}

Povžetek: Avtor aplicira teorijo resonance Hartmuta Rosa. Pokaže, da Rosov pojem resonance omogoča teoretsko poglobitev razumevanja bivanjskega smisla in upanja ter njuno koristno osvetlitev. Struktura članka: najprej avtor pojasni fenomene resonance, bivanjskega upanja in bivanjskega smisla. Na tej podlagi utemelji trditev, da bivanjski smisel temelji na resonanci, saj predpostavlja vse bistvene značilnosti resonance. Iz tega izhaja, da je predmet teženja našega bivanjskega upanja resonanca, saj brez resonance ni bivanjskega smisla, ki pa je neposredni ,predmet' teženja bivanjskega upanja.

Ključne besede: Hartmut Rosa, resonanca, odtujenost, bivanjski smisel, bivanjsko upanje

Abstract: The author applies Hartmut Rosa's resonance theory. He shows that Rosa's notion of resonance enables a theoretical deepening of the understanding of the meaning of life and hope, as well as their useful illumination. The article's structure is as follows: First, the author explains the phenomena of resonance, existential hope and meaning of life. On this basis, he substantiates the thesis that the meaning of life is grounded in resonance, as it presupposes all the essential characteristics of resonance. It follows that the object of the aspiration of our existential hope is resonance because without resonance, there is no meaning of life, and this is the direct, object' of the aspiration of existential hope.

Keywords: Hartmut Rosa, resonance, alienation, the meaning of life, existential hope

\footnotetext{
Raziskovalni program Etično-religiozni temelji in perspektive družbe ter religiologija v kontekstu sodobne edukacije in nasilje (P6-0269) in temeljni raziskovalni projekt Holistični pristop k spoštovanju človekovih pravic $v$ gospodarstvu - reforma slovenske in mednarodne pravne ureditve (J5-1790) je odobrila in finančno podprla Javna agencija za raziskovalno dejavnost Republike Slovenije (ARRS). Članek je nastal v okviru omenjenega programa in projekta. Agenciji se za podporo zahvaljujemo.
} 


\section{Uvod}

Glavni pojmi, okrog katerih se suče razmislek v tem članku, so resonanca, bivanjski smisel in upanje. V tem kontekstu apliciramo teorijo resonance, ki jo je razvil nemški sociolog Hartmut Rosa (Rosa 2016; 2019a; 2019b; 2019c). Takšna zastavitev je izredno relevantna in aktualna, saj je Rosa s svojo teorije resonance v zadnjih letih vzbudil izredno veliko zanimanja (Peters in Schulz, ur. 2017; Kläden in Schüßler, ur. 2017; Wils, ed. 2019; Rosa in Henning, ur. 2019; Klun 2020). Tema resonance je po njegovi zaslugi postala $v$ tem trenutku ena najbolj vročih tem $v$ humanistiki in v družboslovju. To ne preseneča, saj je poglobljeno in pravilno razumevanje resonance odločilnega pomena za razumevanje in reševanje ključnih in temeljnih problemov sodobnega sveta. Ti problemi se kažejo na različnih ravneh. Na najbolj temeljni in globalni ravni lahko omenimo ekološki izziv. Nujno potrebujemo spremembo gole instrumentalne drže do naravnega okolja (Globokar 2018; Nguyen et al. 2020, 181): ne samo na ravni posameznikov in nekaterih skupin, ampak na sociološko relevantni ravni. Resonančni odnos do naravnega sveta pomeni dober temelj za takšno novo držo. Na družbenopolitični ravni lahko omenimo problem antidemokratičnih populističnih gibanj, ki ogrožajo našo, zahodno, liberalno demokracijo. Kakor je opozoril Charles Taylor (Taylor 2019, 75-79), teh gibanj ni mogoče ustrezno razumeti brez pojma resonance. Na zasebni in socialni ravni lahko omenimo zaskrbljujočo razširjenost duševnih bolezni, depresije in izgorelosti v moderni družbi gmotne blaginje, ki so posledica odtujenosti kot odsotnosti resonance. Poleg tega za pomemben del Rosove teorije lahko rečemo, da je nekakšna ,sociologizacija' teologije. Kakor je ugotovil že Martin Laube, je skrivnost uspeha, zanimivosti, privlačnosti in popularnosti Rosove teorije resonance v tem, da nekatere pomembne krščanske teološke teme obdela v sociološki preobleki (Laube 2018, 363). ${ }^{2}$

Lahko razlikujemo več vrst in razsežnosti upanja (Sorč 2003, 393-418; Pieper 2002, 90-93; Davenport 2008, 198; 202 ). Tudi izraz smisel je homonim. V tem članku nas zanima bivanjsko upanje, ki je upanje, da ima naše življenje bivanjski smisel. V nadaljevanju bomo izraz smisel uporabljali v smislu bivanjskega smisla, izraz upanje pa v smislu bivanjskega upanja. Pokazali bomo, da Rosov pojem resonance omogoča teoretsko poglobitev razumevanja smisla in upanja ter njuno koristno osvetlitev. Struktura članka: najprej pojasnimo fenomene resonance, upanja in smisla. Na tej podlagi utemeljimo tezo, da smisel temelji na resonanci, saj predpostavlja vse bistvene značilnosti resonance. Iz tega izhaja, da je predmet teženja našega upanja resonanca, saj brez resonance ni smisla, smisel pa je neposredni ,predmet' teženja upanja.

Glede antropoloških vidikov sodobne (duhovne) situacije z vidika teologije glej Petkovšek 2019, z vidika pomena upoštevanja tradicije $v$ kontekstu sekularizacije Vodičar 2020. Poseben izziv pomeni sodobna tehnologija, tudi z aspekta resonance in odtujenosti, še posebno v smislu razpolaganja s človekom (Strahovnik, Miklavčič in Centa 2020). Resonanca je ključni dejavnik človekove rezilience (Žalec 2020, 275), glede pomena slednje z vidika psihologije in psihoterapije glej Erzar 2020. O pomenu resonance v okviru prenašanja vere na otroke glej Platovnjak 2020. Za obravnavo odtujitve v biblijskem kontekstu glej Roubalová et al. 2021, 72. 


\section{Glavne značilnosti in sestavine resonance in odtujenosti}

Rosa je svoj pojem resonance in resonančno sociologijo našega odnosa do sveta predstavil v različnih publikacijah. Najpomembnejša je njegova knjiga Resonanca: sociologija našega odnosa s svetom (Rosa 2016; angleški prevod Rosa 2019c). Razvil je odnosno teorijo naše biti-v-svetu. Ta teorija črpa iz različnih virov in združuje tako pridobljene elemente $v$ integralno teorijo. Morda je za nekatere Rosova pripadnost kritični teoriji najbolj opazna, vendar njegova teorija veliko dolguje tudi različnim drugim miselnim tokovom: fenomenologiji, personalizmu in odnosni misli na splošno. Od kritične teorije je treba najprej omeniti Herberta Marcuseja, Theodorja W. Adorna in Ericha Fromma, od fenomenologov Martina Heideggerja in od personalistov Martina Bubra.

Rosa je razvil poseben model biti-v-svetu (Rosa 2019b 197-198; 2019c, 145), ki presega dualizem subjekta in objekta. To nas seveda takoj spomni na Heideggerja, vendar pa je morda glavni predhodnik Rosove teorije Bubrova filozofija jaz - ti in jaz - ono odnosa, ki jo je Buber zasnoval že leta 1907 (Buber 1955, xiii; Buber 1999, 236-237), proslavil pa s svojim odmevnim delom Jaz in ti (1923; Buber 1995), ki je izšlo štiri leta pred Heideggerjevim prelomnim delom Bit in čas (1927; Heidegger 1997).

Rosa izpostavlja štiri konstitutivne momente resonance (Rosa 2019b, 196): 1. aficiranost, dotaknjenost, da se udeleženca resonance nekaj dotakne (Affizierung); 2. lastno učinkovanje (Selbstwirksamkeit); 3. preobrazba (Transformation); 4. nerazpoložljivost (Unverfügbarkeit) (Rosa, 2018; 2019d). Zadnji moment kaže na še neko podobnost med Rosovo teorijo in Heideggerjevo filozofijo.

Aficiranost pomeni, da je resonanca nasprotje ločenosti, nevplivanosti, indiferentnosti, tudi ravnodušnosti. O resonanci ne moremo govoriti, če nista $v$ njej aficirani obe strani $v$ odnosu. Zelo pomembno je, da se zavedamo: resonanca je dvostranski ali obojestranski odnos (Rosa 2019a, 27). To pa nas že napoti na drugi konstitutivni moment, lastno učinkovanje, ki pomeni, da noben deležnik v resonančnem odnosu ni pasiven, ni nedejaven. $V$ resonanci ni noben deležnik zgolj objekt, ampak je vsak deležnik tudi že subjekt. To je še podobnost med resonanco in Bubrovim jaz - ti odnosom. Govorimo o zelo zelo podobni, če ne že kar isti poanti. Po Bubru v jaz - ti odnosu ni bistvo to, da bi mi entiteto, s katero smo v jaz - ti odnosu, samo raziskali kot pasivni predmet raziskave. Pri jaz - ti odnosu se zgodi, da se nam entiteta, s katero smo v odnosu, razpre, odpre, zasvetlika, kakor pravi Buber $(1999,100)$, v svoji celoti in enotnosti $(1995,120)$. Entiteta, ki jo, odkrivamo, je sama aktivna, se nam sama razpira, odnos jaz - ti jo samo pripravi do tega (1999, 100). Dodatna podobnost med jaz - ti odnosom in resonanco je $v$ tem, da imamo lahko oba odnosa, tako jaz - ti odnos, kakor ga pojmuje Buber, kakor resonanco, kakor jo pojmuje Rosa, načeloma do vsake entitete: do žive, nežive, do živali, do stvari, do rastline, do človeka, do sveta kot celote, do Boga itd. $(1995,118)$ Bubrov jaz - ti odnos sta na primer tudi jaz - ti odnos do stroja (vedno bolj relevanten v današnji tehnološki dobi) in pa odnos do svetovnega dogajanja $(1999,152)$. Zato 
je na dlani pomen razvijanja jaz - ti odnosa oziroma resonančnega odnosa za ekološki odnos do naravnega okolja.

Naslednji konstitutivni moment resonance je preobrazba. Tu se spet izrazi dvostranska narava resonančnega odnosa. Resonanca je odnos, ki preobrazi oba deležnika v njem. Tudi to je skupna točka z Bubrovim jaz - ti odnosom. Naslednja skupna značilnost z jaz - ti odnosom je, da resonance ne moremo poljubno proizvajati in nadzorovati. Resonanca se, tako kakor jaz - ti odnos, izmika kontroli. Resonančni odnos zato pomeni delno izgubo avtonomije. (Rosa 2019a, 27)

Nemožnost nadzora resonance je sestavni del njenega četrtega konstitutivnega momenta, nerazpoložljivosti (Rosa 2019b, 200-201). V pogledu nerazpoložljivosti je pomembna distinkcija med prilaščanjem in prilagojeno preobrazbo ( $A n-$ verwandlung, tudi anverwandelnde Transformation (2019a, 22); ang. prevod adaptive transformation [2019c]). Prilaščanje je drža oziroma ravnanje, ki želi narediti neko določeno entiteto razpoložljivo. Njeno nasprotje je prilagojena preobrazba, ki je bistvo resonančnega odnosa. Pri prilagojeni preobrazbi govorimo o ,uglasitvi“ s svetom oziroma z neko določeno entiteto, s katero smo v odnosu resonance. Ta prilagoditev je preobrazbena, ker preobrazi oba deležnika v odnosu. To je preobrazbeno srečanje (Begegnung) med obema. (2019a, 14) Razlikovanje med razpoložljivostjo in prilagojeno preobrazbo je podlaga Rosovega poskusa, da bi resonanco vzpostavil kot središčni pojem za zasnutje in utemeljitev odnosne sociologije in teorije našega odnosa s svetom. (14)

Kakor že rečeno, z resonančnim odnosom ne moremo poljubno razpolagati in ga kontrolirati. Paradigmatična zgleda resonančnega odnosa, ki nam to lahko hitro in jasno ilustrirata, sta vera in ljubezen. Vera je v krščanski tradiciji božja milost, ljubezen pa nas zadene na način, ki je zunaj naše (popolne) kontrole. Prav tako se preobrazbeni učinki resonance izmikajo kontroli. (19). Poleg tega z entiteto, do katere zavzamemo prilaščevalni odnos, odnos golega razpolaganja, instrumentaliziranja, inženirske obravnave, ne moremo biti v resonančnem odnosu. Ustreznik Rosovega prilaščevalnega odnosa pri Bubru je jaz - ono odnos, ki je nasprotje jaz - ti odnosa.

Po Rosi je naš temeljni odnos do sveta v mnogih ozirih lahko predkognitiven, vendar pa ni predsocialen. To dejstvo odpira obzorje in prostor za pristno sociologijo človekovih odnosov s svetom. (2019c, 144). Rosov projekt je, kakor smo že omenili, zasnutje in utemeljitev takšne sociologije in teorije.

Osnovni kategoriji našega odnosa do sveta sta po Rosi resonanca in odtujitev (Entfremdung). Rosa ju definira takole:

»Resonanca je tak odnos do sveta, ki se oblikuje $z$ af $\leftarrow$ ektom in čust $\rightarrow$ vom, intrinzičnim interesom in zaznanim lastnim učinkovanjem, v katerem subjekt in svet aficirata drug drugega in se medsebojno preobražata.

Resonanca ni odmev, ampak odziven odnos, ki zahteva, da obe strani govorita s svojim glasom. To je mogoče le, če so prisotna močna vrednotenja. ${ }^{3}$ Resonanca implicira vidik konstitutivne nerazpoložljivosti.

Kakor vidimo, Rosa na ključnem mestu uporablja pojem Charlesa Taylorja ,močno vrednotenje’ (ang. 
Resonančna razmerja zahtevajo, da sta subjekt in svet dovolj ,zaprta' ali konsistentna sama s seboj, da vsak govori s svojim glasom, hkrati pa morata ostati dovolj odprta, da drug na drugega vplivata in se dosežeta.

Resonanca ni čustveno stanje, ampak način odnosa, ki je glede na čustveno vsebino nevtralen. Zato imamo lahko radi žalostne zgodbe.« (174)

\section{Opredelitev odtujenosti}

»Odtujenost označuje specifično obliko odnosa do sveta, v katerem se subjekt in svet soočita $v$ odnosu ravnodušnosti ali sovražnosti (odbijanja) in tako brez kakršnekoli notranje povezanosti. Odtujitev je potemtakem mogoče opredeliti tudi kot odnos brez odnosa (Rahel Jaeggi).

Odtujenost je tako pokazatelj stanja, v katerem sveta ni mogoče ,prilagodljivo preobraziti', zato se vedno zdi hladen, tog, odbojen in neodziven. Resonanca torej tvori ,drugo' odtujenosti - njeno antitezo.

»Depresija ali izgorelost se nanaša na stanje, v katerem so vse osi resonance postale neme in gluhe. Oseba lahko, ima' družino, delo, družabne klube, religijo itd., vendar ji ti več ne ,govorijo'. Subjekt ni več zmožen tega, da bi se ga kaj dotaknilo ali da bi bil aficiran in nima nobenega občutka lastnega učinkovanja. Tako svet kot subjekt sta videti brez življenja, mrtva, prazna.« (Rosa 2019c, 184)

Ko smo v odnosu odtujitve s svetom, je svet nem, ne govori z nami in tudi mi ne z njim (2019a, 16). Med nami in svetom ni nobene komunikacije. Pravi odnos oziroma resonanca je komunikacija, še več, preobrazbena komunikacija, medtem ko je odtujenost, brezodnosni odnos nekaj mrtvega. Odtujenost v tem smislu pomeni izgubo sveta (Weltverlust) (23); to je izguba sveta kot živega partnerja v živem odnosu, ne kot golega predmeta prilaščanja, razpoložljivosti, uporabe ali izrabe.

Rosa razlikuje tri dimenzije ali osi resonance: horizontalno, diagonalno in vertikalno (2019c, 195ff; 2019a, 24-25). Vodoravna razsežnost obsega socialne odnose do drugih ljudi, na primer prijateljstvo in intimne odnose, pa tudi politične odnose. Diagonalna dimenzija obsega odnos do sveta materialnih stvari. Vertikalna razsežnost (2019c, 258ff) je odnos do sveta kot totalitete, ki obsega ali vključuje človekovo celoto (pre)bivanja in življenja (2019a, 24-25; 28ff).

Nasprotje odtujenosti je, kakor že omenjeno, resonanca. Vendar odnos med odtujenostjo in resonanco ni zgolj nasprotje, ampak dialektično razmerje (2019c,

strong evaluation). Subjekt močnega vrednotenja je bitje, za katero niso vse želje enakovredne, ampak svoje želje hierarhizira. Vključuje imetje potreb in želja, ki samemu subjektu teh želja niso všeč, ki jih nizko ali negativno vrednoti. Prav tako pa ima lahko želje, ki so mu všeč. Močno vrednotenje vključuje tako imenovane želje drugega reda, ki vrednotijo subjektove lastne želje: nekatere pozitivno vrednoti, na primer željo, da bi pomagal svojim otrokom, nekatere pa negativno, na primer željo, da bi na drugega preložil svoje delo. Tako ima lahko potrebo po heroinu, ki je želja prvega reda, ker je odvisnik, vendar mu ta potreba in želja nista všeč, ima željo, da ne bi imel te želje, ki je želja drugega reda. (Abbey 2000, 17-26) 
184ff), saj je resonanca možna le na podlagi nemega, odtujenega sveta (190). Resonanca je nasprotje odtujenosti, po drugi strani pa brez odtujenosti ni resonance; v tem oziru resonanca ni alternativa odtujenosti, ampak le blisk v odtujenem svetu. Rosa razlikuje med bliski resonance, posameznimi prigodnimi izkustvi te resonance, ki se občasno pokaže, na eni strani, in trajno osnovno zmožnostjo in senzibilnostjo za resonanco ter trajnim temeljnim zaupanjem v možnost resonance na drugi. (Laube 2018, 366) Takšna zmožnost, Rosa jo imenuje dispozicijska resonanca, in temeljno zaupanje sta potrebna pogoja in eksistencialni temelj za prigodne in neobstojne resonance, ki jih ni mogoče nadzorovati (367).

Kakor smo že omenili, je velika podobnost med Rosovo teorijo resonance in Bubrovo filozofijo jaz - ti odnosa in na tem mestu lahko naša opažanja o afiniteti med njima še dopolnimo. Za Bubra je odnos prvi in temeljni vidik vsega človekovega obstoja. Buber je bil prepričan, da je hrepenenje po odnosu jaz -ti osnovna in glavna človekova potreba (Buber 1995, 6-28; 2002, 31ff; Rosa 2019c, 260-261). $Z$ vidika tematizacije religijskih vidikov resonance se nam zdi pomembno, da na tem mestu dodamo: izkaže se, da je to hrepenenje hrepenenje po Bogu in jaz - ti odnosu z njim (Stres 1999, 282), saj po Bubru človek hrepeni po trajnem jaz - ti odnosu oziroma odnosu resonance, ne le po krhkem, neobstojnem, kakor so njegovi jaz - ti odnosi z ustvarjeninami. Takšen odnos pa je možen le z Bogom. Odnos z Bogom ${ }^{4}$ je temelj in vir vsakega jaz - ti odnosa na svetu ali s svetom. Še več, po Bubrovem mnenju z vsakim jaz - ti odnosom vstopamo bolj ali manj globoko v odnos z Bogom ali vsaj v njegovo preddverje. Dih velikega Ti veje v vsakem jaz - ti odnosu, kakor je zapisal Buber (Buber 1995, 7).

Podobno kakor Buber o jaz - ti odnosu je Rosa prepričan o resonanci, da je temeljna značilnost človeka kot človeka. ${ }^{5}$ Ljudje smo bitja, ki imajo temeljno zmožnost za resonanco in temeljno potrebo po njej. ${ }^{6}$ Tako človeška subjektivnost kakor družbena intersubjektivnost se temeljno oblikujeta z vzpostavitvijo osnovnih resonančnih odnosov in okoli njih (Rosa 2016, 293). Zato sta tako resonanca kakor hrepenenje po resonanci sestavna dela človekove človeškosti in potrebni pogoj njegovega učlovečenja. ${ }^{7}$

Naslednje pomembno dejstvo je, da resonanca ni samo harmonija ali konsonanca, ampak predpostavlja disonanco in razliko. Rosa navaja dialog kot obliko resonančnega odnosa: vsaj za začetek dialoga je potrebna pomembna, netrivialna različnost, ki se manifestira v nasprotju in nasprotovanju. Brez te različnosti ni

4 Ta odnos je vedno odnos jaz - ti, ali bolje: jaz - Ti, kajti samo in edino Bog je tisti, ki ne more postati ono (Stres 1999, 280).

5 Laube opozarja na Rosovo nedoslednost: Rosa pravi, da ne postavlja trditev o bistvu človeške narave. Vendar ko trdi, da je zmožnost, zadovoljiti antropološko potrebo po resonanci, odvisna od možnosti stabilnih resonančnih osi, bi težko rekli, da jih res ne. (Laube 2018, 367, op. 13)

6 Resonanca je bistvena sestavina duhovnosti. Glede velike duhovne lakote v postmoderni kulturi gl. Platovnjak 2017.

7 Zdi se, da Rosa s svojo tezo o antropološki potrebi po resonanci podeduje hermenevtično tezo o človekovi antropološki potrebi po smislu, čeprav je Rosa zelo zadržan glede diskurza smisla (Rosa 2016, 303ff). Laube to zadržanost razlaga s tem, da pojem smisla ne more zajeti momenta preobrazbe, ki je tako pomemben za Rosov pojem resonance (Laube 2018, 367, op. 14). 
možna nobena resonanca. (2019a, 22) Resonanca ni niti popolno strinjanje, pri katerem se ne more razviti noben pravi dialog in v katerem manjka srečanje $z$ drugim glasom, niti golo prerekanje in obtoževanje, v katerem manjkajo ključni konstitutivni momenti resonance: resnična aficiranost, lastno učinkovanje, medsebojna preobrazba oziroma prilagojena preobrazba in odnos neprilaščanja oziroma nerazpoložljvosti.

Poudarili smo že, da je resonanca dvostranski, obojestranski odnos. Brez pripravljenosti za resonanco, brez neke določene odprtosti zanjo pri deležnikih v resonanci resonanca ni možna. Vendar je resonanca nerazpoložljiva in je ne moremo imeti pod nadzorom. Zato pripravljenost za resonančni odnos vključuje pripravljenost za tveganje, da se spustimo v nekaj, za kar ne vemo, kakšne posledice bo imelo. Resonanca predpostavlja pripravljenost za tveganje in ranljivost oziroma pripravljenost, da se naredim ranljivega. Prav tako vključuje, kakor že omenjeno, neko določeno izgubo avtonomije in kontrole nad samim seboj. Resonanca torej implicira ne samo, da ne razpolagam $z$ drugim, s katerim sem $v$ resonanci, ampak tudi, da v celoti ne razpolagam s samim seboj, odpoved težnji, da bi popolnoma razpolagal $\mathrm{s}$ samim seboj in pristanek na to. $\mathrm{V}$ smislu orisane pripravljenosti za resonančni odnos govori Rosa o dispozicijski resonanci oziroma o habitualni pripravljenosti na resonanco. Dispozicijske resonance pa nima tisti - ali pa je zelo nerazvita, poškodovana ali okrnjena -, ki svet dojema kot sovražnega, kajti za čustveno držo, ki ustreza dojemanju sveta kot sovražnega, so značilne čustvena zaprtost, afektivna obrambna naravnanost in pripravljenost za konflikt, boj. (Rosa 2019a, 27-28) Zato je Albert Camus, radikalni mislec absurdnosti človekovega položaja v svetu, ki je menil, da vlada med človekom in svetom absolutna odtujenost, katere ni mogoče prevladati, zapisal, da je absurdnost edino, kar ju povezuje. "Spaja ju tako čvrsto, kakor bitja lahko poveže samo sovraštvo." $(1980,37)$ Resonančna drža do sveta potrebuje neko določeno mero simpatije do sveta ali ljubezni do sveta in dojemanje sveta ne kot nečesa, kar mi je tuje, ampak kar mi je sorodno. Resonančna drža predpostavlja tudi neki določen optimizem, pogum in zaupanje (Rosa 2019c, 416). To trditev v neki meri potrjujejo tudi Rosove besede: dispozicijska odtujenost je lahko tudi posledica umanjkanja ali pomanjkanja izkušnje svojega lastnega učinkovanja. Kdor na podlagi svojih lastnih življenjskih izkušenj izhaja iz tega, da sam sveta ali ,drugega' ne more doseči, ampak se mora naproti njemu uveljavljati ali se pred njim braniti, bo težko gojil resonančno držo. (2019a, 27-28)

\section{Glavne značilnosti smisla}

Bistveno za smisel je, da je to nekaj, kar človek načeloma lahko začuti, ,spozna', doživi, izkusi. Govoriti o smislu, ki je načelno spoznavno ali doživljajsko nedosegljiv človeku, je isto kakor reči, da življenje nima smisla. Smisel je nekaj, kar človek načelno lahko odkrije, tako da to dojame ali doživi. Občutje smisla vključuje občutek izpolnjenosti, pristnega bivanja. 
Smisel je skupna dobrina. Človek ga ne more uživati sam, ampak samo tako, da je v odnosu z neko entiteto kot deloma avtonomno in odzivno. To nam dokazujejo nešteti zgledi depresije kot krize smisla. Depresije ne more pregnati mačka robot, ker vemo, da nima avtonomnosti, ki jo ima prava mačka (2019c, 201). Še bolj kakor živa mačka pa jo lahko prežene človek, ki ima še večjo avtonomijo kakor mačka.

Naslednja značilnost smisla je, da človek z njim ne razpolaga. To pomeni, da ga ne nadzoruje, da ga ne more inženirsko proizvesti. Inženiring smisla ni možen. To se ujema z našo gornjo tezo, da je smisel dosegljiv samo kot skupna dobrina v odnosu z nekim drugim bitjem kot avtonomnim. Smisel implicira tudi preostale tri konstitutivne elemente resonance: lastno učinkovanje, aficiranost in preobrazbo deležnikov v resonanci. Odnos, v katerem doživimo smisel, mora biti takšen, da se nas v njem nekaj dotakne in nas spremeni; toda ne samo nas, ampak tudi entitete, s katero smo v odnosu. To pa zato, ker smiselnost človeškega življenja implicira, da smo na neki način pomembni, da smo dejavnik, da smo ,faktor'. Doseganje smisla torej vključuje aficiranost in preobrazbo obeh udeležencev smisel porajajočega odnosa.

\section{Sklep}

Ugotavljamo, da lahko smisel interpretiramo kot nekaj, kar temelji na resonanci, saj vidimo, da so zanj bistvene vse štiri glavne značilnosti resonance. Ker je smisel neposredni lastni ,predmet' upanja, po katerem ono teži, lahko rečemo, da je tudi resonanca predmet teženja upanja, saj brez resonance ni smisla.

",Proizvodnja smisla' se zgodi tam /.../, kjer začnejo vibrirati žice resonance," je zapisal Rosa (2019b, 199). Resonanca človeku omogoča začutiti smisel, ga nanj usmeri in opozori. Resonanca je človekov vodnik k smislu. Skozi resonanco se človeku intuitivno, neposredno, neteoretsko razkriva smisel. Človek lahko svoje intuitivno razumevanje smisla tudi teoretsko predela, nadgradi in poglobi. Vendar pa lahko resnično razumevanje smisla pride samo iz resonance, enako tudi moč, da smisel, ki se nam je razkril, dejansko živimo. V tem smislu sta tako doživljanje in razumevanje smisla kakor tudi življenje smisla, to, da smisel dejansko živimo, neteoretskega izvora. To pa ne izključuje, da lahko prav teoretsko razmišljanje koga privede do tega, da začne $v$ njem vibrirati žica resonance in začuti smisel.

To pojmovanje se ujema z Rosovim pojmovanjem, da so religije obljuba resonance (2019c, 258). Religije so osi resonance oziroma človeku zagotavljajo osi resonance, ki mu omogočajo, da goji resonančne odnose in iz njih živi. To pa pomeni, da so religije tudi obljube smisla. Rosa postavlja v ospredje ugotovitev, da je človek bitje resonance, vendar vidimo, da je še kako pomemben tudi smisel. Človek hrepeni po smislu, ker pa je smisel brez resonance nedosegljiv, hrepeni po resonanci.

Resonanca sama še ni smiselno življenje ali izpolnitev smisla, tako kakor vest oziroma glas vesti še ni moralno življenje. Je pa, tako kakor vest za moralno živl- 
jenje, nepogrešljivi in najpomembnejši temelj in vodnik za smiselno življenje. Odtujenost je problem, ker v njej izgubljamo ali izgubimo občutek smisla življenja. Takšen občutek ne temelji na teoretskih podlagah, ampak je predteoretske in lahko rečemo - tudi transteoretske narave. Zato ga gola teoretska drža ne more proizvesti. To se ujema z že omenjeno ugotovitvijo, da je občutek smisla življenja nerazpoložljiv, saj je tisto, kar lahko teoretsko (povsem) ,obvladamo' in osvojimo, razpoložljivo.

\section{Reference}

Abbey, Ruth. 2000. Charles Taylor. Teddington: Acumen.

Buber, Martin. 1955. The Legend of the Baal-Shem. Prevedel Maurice Friedman. London: Horovitz Publishing.

- - . 1995. Ich und Du. Stuttgart: Reclam.

- - - 1999. Dialoški princip. Prevedel Janez Zupet. Ljubljana: Društvo 2000.

---. 2002. Between Man and Man. London: Routledge \& Kegan Paul.

Camus, Albert. 1980. Mit o Sizifu: esej o absurdnem. V: Albert Camus, Mit o Sizifu; Uporni človek, 13-135. Prevedel Janez Gradišnik. Ljubljana: Cankarjeva založba.

Davenport, John J. 2008. Faith as Eschatological Trust in Fear and Trembling. V: Edward F. Mooney, ur. Ethics, Love, and Faith in Kierkeg aard, 196-233. Bloomington: Indiana University Press.

Erzar Tomaž. 2020. Stiska, iskanje opore, predanost in razvijanje odpornosti. Bogoslovni vestnik 80, št. 2:415-423.

Globokar, Roman. 2018. Krščanski antropocentrizem in izkoriščevalska drža človeka do naravnega okolja. Bogoslovni vestnik 78, št. 2:349364.

Heidegger, Martin. Bit in čas. 1997. Prevedli Tine Hribar et al. Ljubljana: Slovenska matica.

Kläden, Tobias, in Michael Schüßler, ur. 2017. Zu schnell für Gott? Theologische Kontroversen zu Beschleunigung und Resonanz. Freiburg: Herder.

Klun, Branko. 2020. Rezilienca in resonanca: v iskanju nove drže do sveta. Bogoslovni vestnik 80 , št. 2:281-292.

Laube, Martin. 2018. „Eine bessere Welt ist möglich": Theologische Überlegungen zur Resonanztheorie Hartmut Rosas. Pastoraltheologie 107:356-370.

Nguyen, Thuc Thi, Quy Thi Thanh Truong, Michal Valčo, Maria A. Khvatova in Andrey Tyazhelnikov. 2020. Christian Theological Views on Industrial Revolutions and Related Ethical Challenges: A Western (And a Global) Perspective. Bogoslovni vestnik 80, št. 1:177-190.

Peters, Christian Helge, in Peter Schulz, ur. 2017. Resonanzen und Dissonanzen: Hartmut Rosas kritische Theorie in der Diskussion. Bielefeld: Transcript Verlag.

Petkovšek, Robert. 2019. Teologija pred izzivi sodobne antropološke krize: preambula apostolske konstitucije Veritatis gaudium. Bogoslovni vestnik 79, št. 1:17-31.

Pieper, Josef. 2002. Upanje. V: Vera, upanje, ljubezen, 73-118. Prevedel Janez Zupet. Ljubljana: Družina.

Platovnjak, Ivan. 2017. Vpliv religije in kulture na duhovnost in obratno. Bogoslovni vestnik 77, št. 2:337-344.

- - . 2020. Družine s predšolskimi otroki potrebujejo pri svojem poslanstvu posredovanja vere več razumevanja, sprejetosti in bližine $v$ Cerkvi na Slovenskem. Bogoslovni vestnik 80 , št. 2:355-370.

Rosa, Hartmut. 2016. Resonanz: Eine Soziologie der Weltbeziehung. Berlin: Suhrkamp.

- - -. 2017. Gelingendes Leben in der Beschleunigungsgesellschaft: Resonante Weltbeziehungen als Schlüssel zur Überwindung der Eskalationsdynamik der Moderne. V: Tobias Kläden in Michael Schüßler, ur. Zu schnell für Gott? Theologische Kontroversen zu Beschleunigung und Resonanz, 18-51. Freiburg: Herder.

- - . 2018. Unverfügbarkeit. Dunaj: Residenz Verlag.

- - . 2019a. Resonanz als Schlüsselbegriff der Sozialtheorie. V: Wils 2019, 11-30.

- - - 2019b. Zur Kritik und Weiterentwicklung des Resonanzkonzepts. V: Wils 2019, 191-212.

- - . 2019c. Resonance: A Sociology of our Relationship to the World. Prevedel James C. Wagner. Cambridge \& Medford: Polity Press.

- - . 2019d. The Uncontrollability of the World. Cambridge: Polity Press. 
Rosa, Hartmut, in Christoph Henning, ur. 2019. The Good Life Beyond Growth: New Perspectives. New York: Routledge.

Roubalová, Marie, Roman Králik, Natalia A. Zaitseva, George S. Anikin, Olga V. Popova in Peter Kondrla. 2021. Rabbinic Judaism's Perspective on the First Crimes Against Humanity. Bogoslovni vestnik 81, št. 1:57-74.

Sorč, Ciril. 2003. Božje kreposti. V: Ciril Sorč, ur. Priročnik dogmatične teologije. Zv. 2, 343-446. Ljubljana: Družina.

Strahovnik, Vojko, Jonas Miklavčič in Mateja Centa. 2020. Etični vidiki uporabe algoritemskega odločanja in ostalih sistemov UI v času pandemij oz. izrednih razmer. Bogoslovni vestnik 80 , št. 2:321-334.
Stres, Anton. 1999. Pomen Bubrove filozofije dialoga. V: Martin Buber. Dialoški princip, 247-290. Ljubljana: Društvo 2000.

Taylor, Charles. 2019. The Ethical Implications of Resonance Theory. V: Jean-Pierre Wils, ur. Resonanz. Im interdisziplinären Gespräch mit Hartmut Rosa, 71-85. Baden-Baden: Nomos.

Vodičar, Janez. 2020. Kritika sekularizacije: tradicija kot pot do trdožive prihodnosti. Bogoslovni vestnik 80 , št. 2:253-266.

Wils, Jean-Pierre, ur. 2019. Resonanz: Im interdisziplinären Gespräch mit Hartmut Rosa. Baden-Baden: Nomos.

Žalec, Bojan. 2020. Rezilienca, teologalne kreposti in odzivna Cerkev. Bogoslovni vestnik 80, št. 2:267-279. 